\title{
A case of immunotactoid glomerulopathy with false-negative $\lg G$ staining
}

\author{
Shuma Hirashio ${ }^{1,2}$, Takahiro Arima ${ }^{2}$, Ayaka Satoh², Kouichi Mandai ${ }^{3}$, Shigeo Hara ${ }^{4}$ and Takao Masaki ${ }^{*}$
}

\begin{abstract}
Background: Immunotactoid glomerulopathy (ITG) is a rare glomerulonephritis characterized by microtubular deposits. Immunofluorescence findings are necessary to differentiate ITG from other proliferative glomerular diseases. The characteristic tubular structure on electron microscopy is essential for a definitive diagnosis, and the diameter of the structure has been traditionally used for differentiating between ITG and other types of glomerulonephritis with organized deposits. In recent years, the disease concept of monoclonal gammopathy of renal significance, which is associated with M protein produced by plasma cell tumors, has been proposed.
\end{abstract}

Case presentation: This was a peculiar case of ITG with underlying monoclonal gammopathy in which lgG showed a false-negative result with immunofluorescence using frozen sections. Additional examinations using a different clone of the anti-lgG antibody revealed typical IgG staining. C4d was strongly positive, consistent with immune complex type glomerulonephritis.

Conclusions: This case highlights unusual features of ITG, and provides a practical hint to avoid a diagnostic pitfall.

Keywords: Immunotactoid glomerulopathy, False-negative, Monoclonal gammopathy of undetermined significance, Monoclonal gammopathy of renal significance

\section{Background}

Immunotactoid glomerulopathy (ITG) is a rare glomerulonephritis characterized by the appearance of a membranoproliferative pattern, negative amyloid staining, and a characteristic ultrastructure on electron microscopy [1]. ITG was initially considered the same as fibrillary glomerulonephritis, a type of glomerulonephritis with organized deposits comprising randomly disposed fibril substructures [2]. Recent studies suggest that ITG and fibrillary glomerulonephritis are two distinct entities [3-5]. Deposits in fibrillary glomerulonephritis lack the microtubular structure, which is a fundamental feature of ITG, and the diameter of the organized deposits in ITG tend to be greater than that in fibrillary glomerulonephritis [6]. With light microscopy, ITG mainly exhibits a membranoproliferative-like injury pattern, and specific diseases enter the differential diagnosis; for example, cryoglobulinemic glomerulonephritis, light-chain deposition disease, fibronectin glomerulopathy, and C3

\footnotetext{
* Correspondence: masakit@hiroshima-u.ac.jp

${ }^{1}$ Department of Nephrology, Hiroshima University Hospital, 1-2-3 Kasumi,

Minami-ku, Hiroshima 7348551, Japan

Full list of author information is available at the end of the article
}

glomerulopathy. To differentiate proliferative glomerulonephritis from other disease entities, diagnosis of ITG requires combined immunofluorescence studies and electron microscopy $[7,8]$. In the diagnosis of glomerulonephritis, immunofluorescence studies of frozen sections provide critical information on the components of the immune complexes. In ITG, IgG, C3, and, less frequently, C1q, are positive in the mesangium and capillary walls $[8,9]$.

Here we describe a peculiar case of ITG that showed $\mathrm{C} 3$ and C1q staining on initial studies. Subsequent studies, however, revealed glomerular IgG positivity using a different clone of the anti-IgG antibody. This case highlights a diagnostic pitfall in the interpretation of immunofluorescence studies, especially in the diagnosis of C3 glomerulopathy.

\section{Case presentation}

The patient was a 69-year-old man with no history of urinary abnormalities or renal dysfunction. When he was 68, he underwent his first health checkup in several years and was found to have occult blood in his urine, proteinuria, and renal dysfunction. Urinalysis at the first examination showed urine protein of $0.49 \mathrm{~g} / \mathrm{gCr}$, urine 
red blood cells of 30-49/high-power field, and pathological granular casts, for which we decided to perform further studies including a renal biopsy. The patient had a history of untreated dyslipidemia. His family history was unremarkable. The patient was not taking any regular medication at the time of the first examination. Physical findings at the first examination were unremarkable. His blood pressure was normal $(112 / 66 \mathrm{mmHg})$. There was no edema, lymph node involvement, splenomegaly, purpura, or bone pain. Table 1 shows the results of urinary and blood analyses on admission for the purposes of the renal biopsy (dipstick test for occult blood $2+$, urine protein $2+$, and urine protein-to-creatinine ratio $0.30 \mathrm{~g} / \mathrm{g}$ on a spot measurement). The number of dysmorphic red blood cells was 20-29 per high-power field. There were no abnormalities in complete blood count or the blood coagulation system. Serum urea nitrogen was $14.9 \mathrm{mg} / \mathrm{dL}$, serum creatinine was $1.19 \mathrm{mg} / \mathrm{dL}$, and estimated glomerular filtration rate by creatinine was $47.6 \mathrm{~mL} / \mathrm{min} / 1.73 \mathrm{~m}^{2}$. Serum cystatin $\mathrm{C}$ level was $1.73 \mathrm{mg} / \mathrm{L}$ and estimated glomerular filtration rate by cystatin was $37.1 \mathrm{~mL} / \mathrm{min} / 1.73 \mathrm{~m}^{2}$. Immunoglobulin levels were normal. Autoantibodies were negative. Serum and urine monoclonal immunoglobulin (immunofixation electrophoresis) were positive. The serum levels of the IgG $\mathrm{\kappa}$ and $\lambda$ chains were $31.40 \mathrm{mg} / \mathrm{dL}$ and $33.60 \mathrm{mg} / \mathrm{dL}$, respectively. The $\mathrm{k} / \lambda$ ratio was 0.935 . Serum cryoglobulin was negative.

With light microscopy, 54 glomeruli were observed, and two glomeruli showed global sclerosis. The remaining glomeruli were enlarged and showed lobular accentuation. In addition to mesangial cell proliferation, all glomeruli showed prominent endocapillary hypercellularity (Fig. 1a-e). Neutrophils and eosinophils showed marked infiltration. There was no hyaline thrombus, crescent formation, and double contour of the capillary walls. Interstitial fibrosis and tubular atrophy was mild. Direct fast scarlet staining was negative. Immunofluorescence was positive for C3 (1+) and $\mathrm{Clq}(2+)$ along the glomerular capillaries. However immunoglobulin G (IgG) was negative. The clone we used to originally test for IgG was produced by Medical \& Biological Laboratories Co., Ltd. (Lot No. 104AG; Aich, Japan). All immunoglobulins were negative (Fig. 1f). Electron microscopy revealed marked endocapillary hypercellularity. There was infiltration of polymorphonuclear leukocytes and monocytes, occluding glomerular capillary lumens. In the subendothelial space, there were many tubular structures in parallel arrays. With higher magnification, the microtubules had a hollow core and the diameter was approximately $40 \mathrm{~nm}$ (Fig. 1g). Most of the deposits contained microtubular structures.

Based on the characteristic electron microscopy findings, ITG was suspected; however, negative staining for immunoglobulins was an unusual finding for ITG. IgG
Table 1 Laboratory results on admission

\begin{tabular}{|c|c|c|}
\hline Parameter & Value & Reference range \\
\hline \multicolumn{3}{|l|}{ Urine } \\
\hline Red blood cell (/HPF) & $50-99$ & $<5$ \\
\hline Urine protein/creatinine ratio (g/g) & 0.32 & $<0.15$ \\
\hline Urine protein electrophoresis & Positive $(\kappa \& \lambda)$ & Negative \\
\hline \multicolumn{3}{|l|}{ Blood } \\
\hline Leukocyte count $(/ \mu \mathrm{L})$ & 7600 & 4500-9000 \\
\hline Hemoglobin (g/dL) & 13.0 & $13.6-17.0$ \\
\hline Platelet count $\left(\times 10^{4} / \mu \mathrm{L}\right)$ & 32.1 & $14-36$ \\
\hline Urea nitrogen (mg/dL) & 14.9 & $8.0-22.0$ \\
\hline Creatinine (mg/dL) & 1.19 & $0.60-1.10$ \\
\hline Uric acid (mg/dL) & 6.8 & $3.6-7.0$ \\
\hline Total protein (g/dL) & 7.2 & $6.7-8.3$ \\
\hline Albumin (g/dL) & 4.1 & $4.0-5.0$ \\
\hline Lactate dehydrogenase (IU/L) & 162 & $119-229$ \\
\hline Sodium (mEq/L) & 140 & $138-146$ \\
\hline Potassium (mEq/L) & 4.8 & $3.6-4.9$ \\
\hline Chloride (mEq/L) & 104 & 99-109 \\
\hline Corrected serum calcium (mg/dL) & 9.3 & $8.6-10.4$ \\
\hline Phosphate (mg/dL) & 3.2 & $2.5-4.7$ \\
\hline C-reactive protein (mg/dL) & 0.06 & $<0.30$ \\
\hline $\operatorname{lgG}(\mathrm{mg} / \mathrm{dL})$ & 1045 & $870-1700$ \\
\hline $\lg \mathrm{A}(\mathrm{mg} / \mathrm{dL})$ & 317 & $110-410$ \\
\hline $\operatorname{lgM}(\mathrm{mg} / \mathrm{dL})$ & 444 & $33-190$ \\
\hline $\lg \mathrm{E}(\mathrm{IU} / \mathrm{mL})$ & 131.9 & $<269$ \\
\hline light-chain type $\mathrm{k}$ (mg/L) & 31.40 & $2.42-18.92$ \\
\hline type $\lambda(\mathrm{mg} / \mathrm{L})$ & 33.60 & $4.44-26.18$ \\
\hline Serum protein electrophoresis & Positive $(\kappa \& \lambda)$ & Negative \\
\hline $\mathrm{CH} 50(\mathrm{CH} 50 / \mathrm{mL})$ & 41.5 & $25-48$ \\
\hline C3 (mg/dL) & 115 & $65-135$ \\
\hline $\mathrm{C} 4$ (mg/dL) & 35 & $13-35$ \\
\hline IC (C1q) ( $\mu \mathrm{g} / \mathrm{mL})$ & $<1.5$ & $<1.5$ \\
\hline Cryoglobulin & Negative & Negative \\
\hline Anti-nuclear antibody & $<80 x$ & $<80 x$ \\
\hline Anti-ds DNA antibody (IU/mL) & 2.5 & $<10.0$ \\
\hline PR3-ANCA (U/mL) & $<1.0$ & $<3.5$ \\
\hline MPO-ANCA (U/mL) & $<1.0$ & $<3.5$ \\
\hline Anti-GBM antibody (U/ml) & $<7.0$ & $<7.0$ \\
\hline Tissue of bone marrow & Normal tissue $\mathrm{cc}$ & mponent \\
\hline
\end{tabular}

HPF high-power field, WF whole field, IgG immunoglobulin G, IgA immunoglobulin $\mathrm{A}$, IgM immunoglobulin $\mathrm{M}$, IgE immunoglobulin $\mathrm{E}, \mathrm{C} 1 \mathrm{~g}-\mathrm{IC} \mathrm{C} 1 \mathrm{q}$ binding lgG immune complex, $d s$ double stranded, $P R 3$ proteinase $3, M P O$ myeloperoxidase, ANCA antineutrophil cytoplasmic antibodies, GBM glomerular basement membrane

detection by paraffin-immunofluorescence following pronase pretreatment was strongly positive within the capillary spaces of a glomerulus (Fig. 1h). Immunofluorescence 


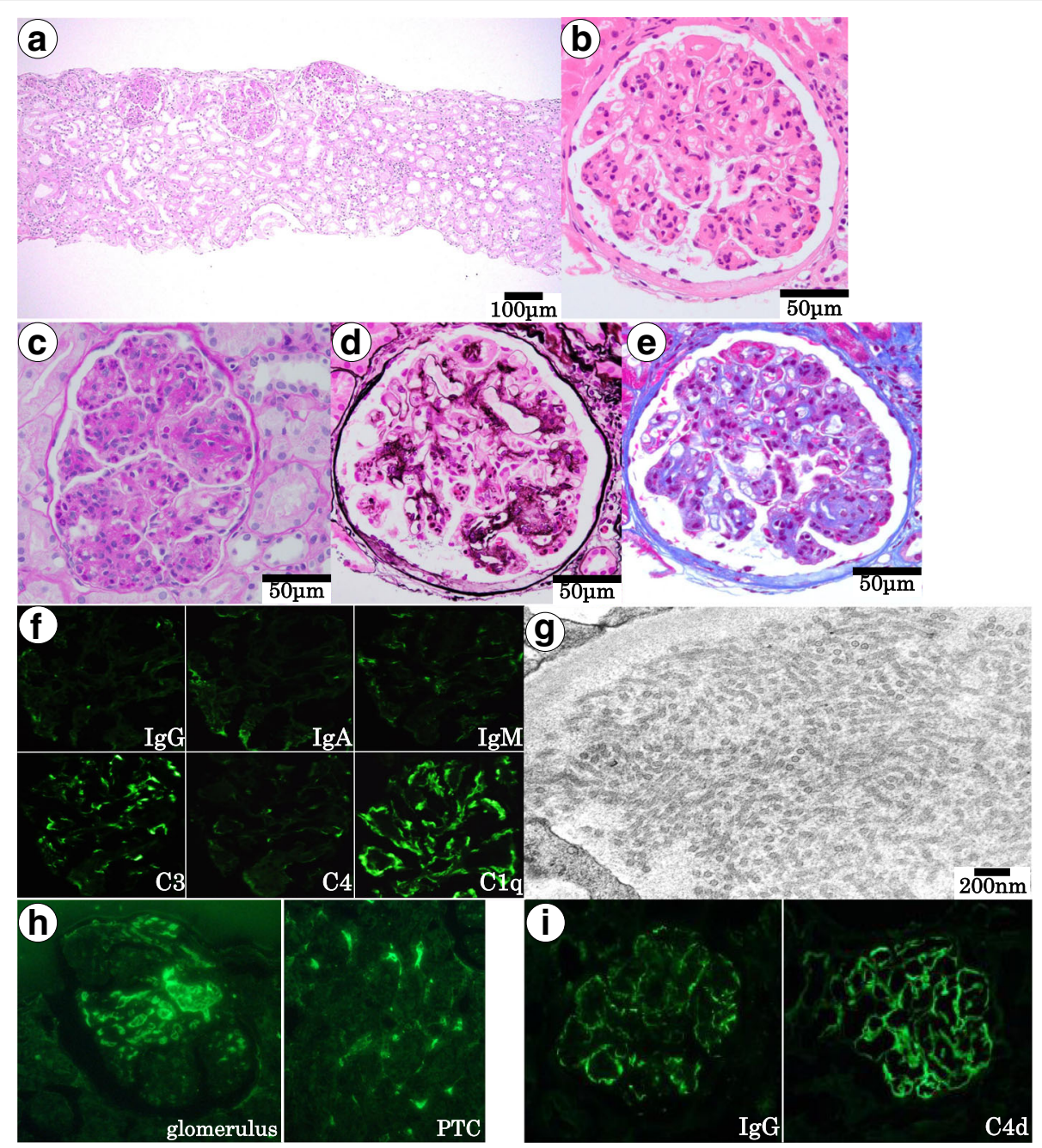

Fig. 1 Diagnostic studies. (a) Periodic acid-Schiff (PAS) staining at a low magnification $(\times 100)$. All glomeruli exhibited lobular accentuation. (b-e) Glomerular images of (b) hematoxylin-eosin, (c) PAS, (d) Periodic acid-methenamine-silver, and (e) Masson's trichrome staining ( $\times 400)$. Glomeruli show endocapillary hypercellularity with neutrophilic and eosinophilic infiltration. Scale bar: $100 \mu \mathrm{m}$ (a) and $50 \mu \mathrm{m}$ (b-e). (f) Immunofluorescence studies using frozen sections. Immunoglobulins were negative. C3 (1+) and C1q (2+) were positive on glomerular capillaries. (g) Electron microscopy image. Cross-sectional view of deposits with microtubular structures. The distribution of these structures was segmental. Scale bar: $200 \mathrm{~nm}$. (h) IgG detection by paraffin-immunofluorescence following pronase pretreatment. The left panel is a glomerulus, and the right panel is a peritubular capillary. The positive signal in the microcapillary lumen was considered to be nonspecific staining for plasma components. (i) Immunofluorescence studies using anti-lgG (left panel, 55,144, MP Biomedicals) and anti-C4d (right panel) antibodies. IgG and C4d were positive on glomerular capillaries, corresponding to staining patterns for C3 and C19

examination of frozen sections using a different clone of anti-IgG antibody (55,144; MP Biomedicals, Tokyo, Japan) showed positive staining in capillary walls. Immunofluorescence for C4d was positive along glomerular capillaries (Fig. 1i). Collectively, the patient was diagnosed with ITG with false-negative IgG staining.

Additional laboratory data revealed that serum and urine were positive for monoclonal immunoglobulins. In a bone marrow biopsy specimen, the proportion of plasma cells was $1.6 \%$, excluding plasma cell myeloma. Chromosomal aberrations were not found. 18F-fluoro-deoxy-glucose positron emission tomography demonstrated no significant uptake.

\section{Discussion and conclusions}

ITG is a primary glomerular disease first reported in 1977 by Rosenmann and Eliakim [10]. It is prevalent in Caucasians, accounting for nearly $0.1 \%$ of renal biopsy cases. ITG is considered less prevalent in Japan. In general, patients with ITG are likely to have progressive renal dysfunction, and approximately $50 \%$ have nephrosis and/or hypertension [6]. Treatment for this condition is generally considered ineffective, although a study reported an amenable effect with steroid treatment in some patients [11].

Electron microscopy is the gold standard for the diagnosis of ITG. Ultrastructural findings in the current case 
were consistent with ITG (presence of typical tubular structures with a small hollow core inside on short-axis view) $[8,9]$. Negative IgG staining is an unusual finding in ITG $[8,12]$, although some reports have described negative glomerular IgG staining in otherwise typical ITG [13, 14]. Given the possibility of a false-negative result in the initial study using the polyclonal anti-IgG antibody, we conducted IgG staining using a different anti-IgG clone, which revealed positive staining in glomeruli. In addition, C4d was positive in glomeruli, consistent with the features in immune complex type glomerulonephritis [15]. Masked immune deposits in membranous-like nephropathy and membranoproliferative glomerulonephritis have been recently reported $[16,17]$, indicating the potential diagnostic pitfalls in immunofluorescence studies. In the current case, IgG staining of paraffin-immunofluorescence following pronase pretreatment could not be evaluated because of nonspecific staining of residual serum within the glomerular capillaries [18]. In our case, the successful immunofluorescence study with the application of a different antibody clone probably reflects recognition of the target epitope by the different antibody clone, not "masked antigens". In addition to pronase digestion, application of different antibody clones to frozen sections may help avoid false negative result in immunofluorescence studies.

A recent study highlights the pathogenetic association between ITG and monoclonal gammopathy due to multiple myeloma and related diseases [19]. Among the pathological conditions regarded as monoclonal gammopathy of undetermined significance without organ dysfunction, monoclonal gammopathy of renal significance has been proposed as a term to refer to a concept of disease manifesting with renal dysfunction during the disease course [20]. Despite the poor proliferative capacity of abnormal plasma cells, monoclonal gammopathy of renal significance is presumably associated with the presence of "dangerous small B-cell clones," which produce the M protein that is highly likely to be deposited in tissue [21]. The importance of early therapeutic interventions for underlying diseases has been highlighted [19]. The current case represents one manifestation of monoclonal gammopathy of renal significance classified as ITG, and highlights the potential diagnostic pitfall with immunofluorescence studies.

In conclusion, we experienced an unusual case of ITG with false-negative IgG deposits. A definitive diagnosis of ITG was made based on electron microscopy findings, and immunofluorescence results were considered a false-negative result for IgG. In addition to pronase digestion in paraffin sections $[15,16]$, application of a different antibody clone, as presented in this report, may be another salvage technique in immunofluorescence studies.
Abbreviation

ITG: Immunotactoid glomerulopathy

\section{Acknowledgements}

We thank Alexander Pishief, LLB, BBmedSc, from Edanz Group (www.edanzediting.com/ac) for editing a draft of this manuscript.

\section{Availability of data and materials}

The dataset supporting the conclusions of this article is included within the article.

\section{Authors' contributions}

$\mathrm{SH} 1, \mathrm{TA}$, and $\mathrm{AS}$ analyzed and interpreted the patient data regarding the hematological disease and the transplant. SH1 followed the patient and wrote the paper together with TA and AS. KM and SH2 performed the histological examination of the kidney. $\mathrm{SH} 2$ and TM reviewed the tables, took care of the imagery and of the figures. $\mathrm{SH} 1, \mathrm{SH}$, and TM participated to the manuscript draft. $\mathrm{SH} 2$ and TM revised the manuscript. All authors read and approved the final manuscript.

\section{Ethics approval and consent to participate}

This study was conducted according to the guidelines laid down in the Declaration of Helsinki and all procedures involving human subjects were approved by the ethics committee of National Hospital Organization Higashihiroshima Medical Center (the reference number: 29-42). The participant signed a letter of informed consent to allow their data to be stored, as required by the National Hospital Organization Higashihiroshima Medical Center.

\section{Consent for publication}

Written consent to publish this information was obtained from the patient.

\section{Competing interests}

The authors declare that they have no competing interests.

\section{Publisher's Note}

Springer Nature remains neutral with regard to jurisdictional claims in published maps and institutional affiliations.

\section{Author details}

'Department of Nephrology, Hiroshima University Hospital, 1-2-3 Kasumi, Minami-ku, Hiroshima 7348551, Japan. ${ }^{2}$ Department of Nephrology, National Hospital Organization Higashihiroshima Medical Center, Hiroshima, Japan. ${ }^{3}$ Department of Diagnostic Pathology, National Hospital Organization Higashihiroshima Medical Center, Hiroshima, Japan. ${ }^{4}$ Department of Diagnostic Pathology, Kobe University Graduate School of Medicine, Kobe, Japan.

Received: 4 December 2017 Accepted: 24 May 2018

Published online: 15 June 2018

\section{References}

1. Alpers CE. Fibrillary glomerulonephritis and immunotactoid glomerulopathy: two entities, not one. Am J Kidney Dis. 1993;22:448-51.

2. Korbet SM, Schwartz MM, Lewis EJ. Immuotactoid glomerulopathy (fibrillary glomerulonephritis). Clin J Am Soc Nephrol. 2006;1:1351-6.

3. Rosenstock JL, Markowitz GS, Valeri AM, Sacchi G, Appel GB, et al. Fibrillary and immunotactoid glomerulonephritis: distinct entities with different clinical and pathologic features. Kidney Int. 2003;63:1450-61.

4. Alpers $C E$, Kowalewska J. Fibrillary glomerulonephritis and immunotactoid glomerulopathy. J Am Soc Nephrol. 2008;19:34-7.

5. Herrera GA, Turbat-Herrera EA. Renal diseases with organized deposits: an algorithmic approach to classification and clinicopathologic diagnosis. Arch Pathol Lab Med. 2010;134:512-31.

6. Fogo A, Qureshi N, Horn RG. Morphologic and clinical features of fibrillary glomerulonephritis versus immunotactoid glomerulopathy. Am J Kidney Dis. 1993;22:367-77.

7. D'agati VD, Jannette JC, Silva FG. Glomerular disease with paraproteinemia or organoid deposits. In: Atlas of nontumor Pathology. 4. Non-neoplastic Kidney Diseases. Washington, DC: American Registry of Pathology, AFIP: 2005. p. 199-235. 
8. Bridoux F, Hugue V, Coldefy O, Goujon JM, Bauwens M, et al. Fibrillary glomerulonephritis and immunotactoid (microtubular) glomerulopathy are associated with distinct immunologic features. Kidney Int. 2002;62:1764-75.

9. Fogo AB, Lusco MA, Najafian B, Alpers CE. AJKD Atlas of Renal Pathology: Immunotactoid Glomerulopathy. Am J Kidney Dis. 2015;66:e29-30.

10. Rosenmann E, Eliakim M. Nephrotic syndrome associated with amyloid-like glomerular deposits. Nephron. 1977;18:301-8.

11. Minami J, Ishimitsu T, Inenaga T, Ishibashi-Ueda H, Kawano Y, et al. Immunotactoid glomerulopathy: report of a case. Am J Kidney Dis. 1997;30:160-3.

12. Brady HR. Fibrillary glomerulopathy. Kidney Int. 1998;53:1421-9.

13. Narita I, Shimada M, Fujita T, Murakami R, Nakamura M, et al. A case of membranoproliferative glomerulonephritis associated with curved fibril deposition. BMC Nephrol. 2015;16:151.

14. Khandelwal A, Trinkaus MA, Ghaffar H, Jothy S, Goldstein MB. A case report of unusually long lag time between immunotactoid glomerulopathy (itg) diagnosis and diffuse large B-cell lymphoma (DLBCL) development. BMC Nephrol. 2016:17:140.

15. Sethi S, Nasr SH, De Vriese AS, Fervenza FC. C4d as a diagnostic tool in proliferative GN. J Am Soc Nephrol. 2015;26:2852-9.

16. Larsen CP, Ambuzs JM, Bonsib SM, Boils CL, Cossey LN, et al. Membranous-like glomerulopathy with masked lgG kappa deposits. Kidney Int. 2014;86:154-61.

17. Larsen CP, Messias NC, Walker PD, Fidler ME, Cornell LD, et al. Membranoproliferative glomerulonephritis with masked monotypic immunoglobulin deposits. Kidney Int. 2015;88:867-73.

18. Messias NC, Walker PD, Larsen CP. Paraffin IF in the renal pathology laboratory: more than a salvage technique. Mod Pathol. 2015;28:854-60

19. Sethi S, Zand L, Leung N, Smith RJ, Jevremonic D, et al. Membranoproliferative glomerulonephritis secondary to monoclonal gammopathy. Clin J Am Soc Nephrol. 2010;5:770-82.

20. Leung N, Bridoux F, Hutchison CA, Nasr SH, Cockwell P, et al. Monoclonal gammopathy of renal significance: when MGUS is no longer undetermined or insignificant. Blood. 2012;120:4292-5.

21. Bridoux F, Leung N, Hutchison CA, Touchard G, Sethi S, et al. Diagnosis of monoclonal gammopathy of renal significance. Kidney Int. 2015;87:698-711.

\section{Ready to submit your research? Choose BMC and benefit from:}

- fast, convenient online submission

- thorough peer review by experienced researchers in your field

- rapid publication on acceptance

- support for research data, including large and complex data types

- gold Open Access which fosters wider collaboration and increased citations - maximum visibility for your research: over $100 \mathrm{M}$ website views per year

At BMC, research is always in progress.

Learn more biomedcentral.com/submissions 